\title{
REPRESENTACIONES DISCURSIVAS DE LA HOMOSEXUALIDAD EN EL SISTEMA DSM IV ${ }^{3}$
}

\author{
FERNANDA TÉLLEZ VEGA ${ }^{4}$ \\ Universidad Industrial de Santander, UIS. Transversal Metropolitana 9-23. \\ Bucaramanga-Santander. Código postal 68001000 \\ fernandatellezvega@gmail.com
}

\section{RESUMEN}

Este estudio tiene como objetivo resaltar la construcción y significación discursiva que da el sistema DSM IV a la homosexualidad, entendiendo que el significado hace referencia al contenido interno del discurso y la significación concierne al contenido externo (visible) del discurso. La Metodología de investigación se concentra en el análisis de contenidos: discusión, críticas y descripción del método de construcción del manual de diagnóstico de enfermedades mentales en su cuarta revisión. La técnica que se adelantó fue la de análisis de contenidos: identificación del discurso dominante, formas de estilo y evaluación de significantes. Los resultados arrojaron que la forma dominante del discurso es institucional, frente a las formas no discursivas neo sexuales. Además, no se evidencian cambios en el discurso psiquiátrico porque su método de construcción es de retroalimentación circular, es decir, en algún lugar del proceso la homosexualidad será considerada como un trastorno o como un tema de revisión psiquiátrica. La investigación revela que el sistema DSM IV, se ajusta a la construcción discursiva poder-saber ampliamente documentada por Foucault en la

${ }^{3}$ Este documento es el tercero de una investigación sobre homosexualidad que inició en el año 2012. El articulo gira en torno a una línea de investigación central sobre Lenguaje, Discurso y Sociedad que se encuentra en construcción. Con este trabajo se han presentado ponencias en la USACH en el marco del III Congreso "Ciencias, tecnologías y culturas. Diálogo entre las disciplinas del conocimiento. Mirando al futuro de América Latina y el Caribe. Hacia una internacional del conocimiento" en la Universidad de Santiago y en el evento titulado III Encuentro de la Red INAV, I Congreso Internacional Narrativas Audiovisuales: Convergencia mediática, transnacionalización e intercambio cultural organizado por la Red INAV de España.

${ }^{4}$ Universidad Industrial de Santander. Facultad de Ciencias Humanas. Investigación y Extensión UIS. Bucaramanga, Santander. Investigación adjunta a la línea cuatro de GLOTTA: Grupo de investigaciones en didácticas del lenguaje, las lenguas extranjeras y la literatura. Lenguaje, Discurso y Sociedad. Apoya el investigador Wilson Gómez Moreno, contacto: wilgomor@uis.edu.co 
que el discurso dominante ejerce poder sobre las neo sexualidades, las define en un ejercicio del saber inscribiéndolas en un manual diagnóstico.

Palabras clave: Homosexualidad, neo sexualidad, manual diagnóstico, análisis crítico del discurso, análisis de contenidos y construcción discursiva.

\section{DISCOURSE REPRESENTATION OF HOMOSEXUALITY IN THE SYSTEM DSM IV}

\section{ABSTRACT}

The objective of this study is to highlight the construction and discursive significance that the DSM IV system gives to the homosexuality, considering that the meaning alludes to the internal content of the speech and the significance concerns the external (visible) content of the speech. Research methodology focuses on the analysis of contents: discussion, critiques and description of the construction method of the diagnosis manual of mental illnesses in its fourth review. The technique applied was the analysis of contents: identification of the dominant speech, style forms and evaluation of significants. The results showed that the dominant form of the speech is institutional, by the non-discursive neosexual forms. In addition, there is no evidence of changes in the psychiatric speech because its method of construction is circular feedback, that is to say, in any place of the process, homosexuality will be considered as a disorder or as a topic of psychiatric review. The research reveals that the DSM IV system fits to the discursive construction being able-knowing, widely documented by Foucault in which dominant speech exerts power on the neo-sexualities and defines them in an exercise of knowing, registering them in a diagnosis manual.

Key words: Homosexuality, neo-sexuality, Diagnostic manual, critical analysis of discourse, content analysis y discursive construction. 


\section{Introducción}

Es evidente que nada es evidente en relación al discurso; a su análisis, a su contexto, a las relaciones que establece con un sistema de poder y a su existencia misma. "El debilitamiento de las restricciones que pesan sobre la homosexualidad es uno de los rasgos más sobresalientes de la situación moral actual en las sociedades occidentales" (Ariés, 1987, p.3), y dicho debilitamiento se refleja en el discurso. Sin embargo, el aplacamiento de las restricciones en las prácticas psiquiátricas; clínicas y de diagnóstico aún "pertenecen a un régimen Victoriano" (Foucault, 1998, p.10). Sus cursos históricos fingen devoción y escrúpulos, una hipocresía en torno a los temas sexuales que aún continúa.

El sistema DSM IV es en principio una herramienta de diagnóstico. Ubicando el manual en el tiempo y en el espacio, el DSM IV en su revisión de 1995 en castellano se cimienta en la historia de la psiquiatría como la necesidad de clasificar y entender mediante la codificación las enfermedades mentales. Este enfoque de estudio tiene dos problemas: el primero son los métodos para clasificar e incluir enfermedades y el segundo sus implicaciones en la construcción del imaginario colectivo que se forma a partir de los diagnósticos. Este último, denominado discurso es abordado en el presente texto.

El sistema discursivo del Manual diagnóstico y estadístico de los trastornos mentales $\mathrm{DSM}^{5}$ en su versión IV ${ }^{6}$ no incluye de manera directa la homosexualidad como una enfermedad. Para vislumbrar ese cambio en el sistema de referencia se precisa leer la sección titulada Trastornos sexuales y de la identidad sexual para develar su construcción discursiva y sus pretensiones cientificistas, que en sumatoria son un trabajo empírico que menciona el orden de las nuevas cosas que se contabilizan: trastornos y trastornados. Sin embargo, no se revelan elementos que no se tienen en cuentan como los gestos y las palabras del

\footnotetext{
${ }^{5}$ De ahora en adelante se utilizará el término DSM IV para referirse al Diagnostic and Statistical Manual of Mental Disorders: DSM-IV

${ }^{6}$ En esta parte del texto es importante resaltar la cátedra de Michel Foucault de 1970 "el orden del discurso" (Foucault, 1970) en la que se plantea que la construcción de un discurso por parte de un individuo puede ser peligrosa, puesto que las formas institucionales que pesan sobre ese discurso superan y determinan todo el proceso de creación o construcción del discurso mismo. Por ello, el DSM IV como institución que lleva consigo un discurso es un caso de estudio pertinente para el análisis crítico del discurso.
} 
psiquiatra, ni la forma discursiva que se le imprime al que es señalado como histérico o enfermo.

Dicho señalamiento produce una proyección masiva que es generada por el manual diagnóstico al sistema de la vida en sociedad e impacta en el imaginario colectivo. Es decir, se instituye una figuración del homosexual y del neosexual distorsionada que sólo en apariencia es objetiva al tener un carácter científico. El imaginario colectivo también se nutre de la vida material de las neosexualidades y del homosexual, al constatar que el rechazo existe en esferas de apariencia objetiva, sin reconocer que la construcción del manual fue realizada por sujetos.

La historia reciente de la homosexualidad como concepto y como objeto de estudio dibuja un derrotero a seguir. Las manifestaciones academistas al respecto inician con el reconocido artículo de Carl Friedrich Otto Westphal publicado en 1870, en el que el autor describe los sentimientos sexuales contrarios, homosexuales. Foucault (1998) referencia estos sentimientos en su libro titulado Historia de la Sexualidad I como la concepción moderna de la homosexualidad y la marginalidad que se inyecta a la representación discursiva, al considerarse como un tema superado que en la historia moderna aún guarda vestigios de desviación.

Otras publicaciones de carácter significativo para la concepción y construcción discursiva <práctica> son La guía del joven, escrita por William Andrus Alcott en 1833 y Lección sobre la castidad para los jóvenes de autoría de Sylvester Graham en 1834. Los textos anteriormente mencionados proscriben la homosexualidad y la masturbación. Estas publicaciones, que tan sólo son ejemplos de miles de libros que se imprimen para promover una filosofía que difiere de la especulación o de la contemplación, no son distintas a los manuales clínicos porque los dos tipos de textos imparten una construcción discursiva predominantemente moral. Aunque en el manual siquiátrico el lenguaje parezca neutro, estéril y pertinente al léxico científico siguen significantes discursivos conciliatorios. Ahora bien, se debe observar con detenimiento el uso de las palabras que indican la desviación y el cómo valorar o diagnosticar dentro de las premisas del manual. 
La construcción discursiva de un manual entendido como lo más sustancial de lo material, señala su valor de uso o utilidad respecto al individuo; restándole importancia a su filosofía de la no especulación. Es decir, la construcción del poder se instituye en la costumbre o práctica moral. Pero debe tenerse cuidado al asegurar una premisa con tanta rapidez, por ello, la hipótesis central del presente trabajo indica que la representación discursiva del homosexual dentro del Manual Siquiátrico DSM IV sigue siendo la misma que la del primer manual. En otras palabras, la institución del manual sigue validando la homosexualidad como una enfermedad aunque no se diagnostique de manera directa, sino de manera soslayada como homosexualidad egodistónica. Esta hipótesis se soporta en los trabajos de Michael Foucault (1999) y Teun Van Dijk (2000). Es un eco de las investigaciones citadas y es relevante en el sentido de la identificación de las relaciones de poder para construir mecanismos alternativos de discurso, que concilien los imaginarios sociales con los políticos.

"Los manuales son, parafraseando a Van Dijk, acciones de índole política que buscan justificar un orden sexual, la institucionalidad de los hospitales psiquiátricos y el ejercicio mismo de la profesión" (Gamboa, 2006, p.286). Por otra parte:

Michel Foucault ubica los inicios de la moral sexual a finales del siglo XVII, época en que comienza a desaparecer la flexibilidad sexual característica de tiempos anteriores. A la par del surgimiento del capitalismo y de la clase victoriana, se inician cambios que aún permanecen en el imaginario actual. (Gamboa, 2006, p.247).

\section{Metodología}

En primer lugar, se realiza un breve recuento del manual para contextualizar el trabajo que constituye una primera etapa dentro del análisis crítico del discurso. En un segundo momento, se describe el método de elaboración del manual DSM IV. Seguidamente, se evidencia el objetivo del análisis del discurso que es remarcar la relación que existe entre el poder y el saber en la descripción del método de construcción del manual, las críticas al manual y las técnicas del ejercicio del poder. Finalmente, se presentan algunas conclusiones sobre esta primera etapa de discusión, puesto que este texto 
corresponde a una etapa preliminar dentro del análisis crítico del discurso. En la Figura 1. se esquematiza la metodología utilizada en esta investigación.

Es importante resaltar que el armazón metodológico se basa en la sistematización del problema presentado en Norman Fairclough (2002). En este artículo de reflexión solamente se presenta la parte de discusión e identificación, es decir, se acota el método del análisis de contenidos, por tanto, esta es una primera etapa de la investigación enmarcada en la línea del lenguaje, el discurso y la sociedad. El esquema se presenta como ciclo, al señalar la importancia de revisar las interpretaciones a la luz de las teorías de los sistemas discursivos poder-saber en un continuo.

Figura 1. Armazón metodológico. Representaciones discursivas de la homosexualidad en el sistema DSM IV

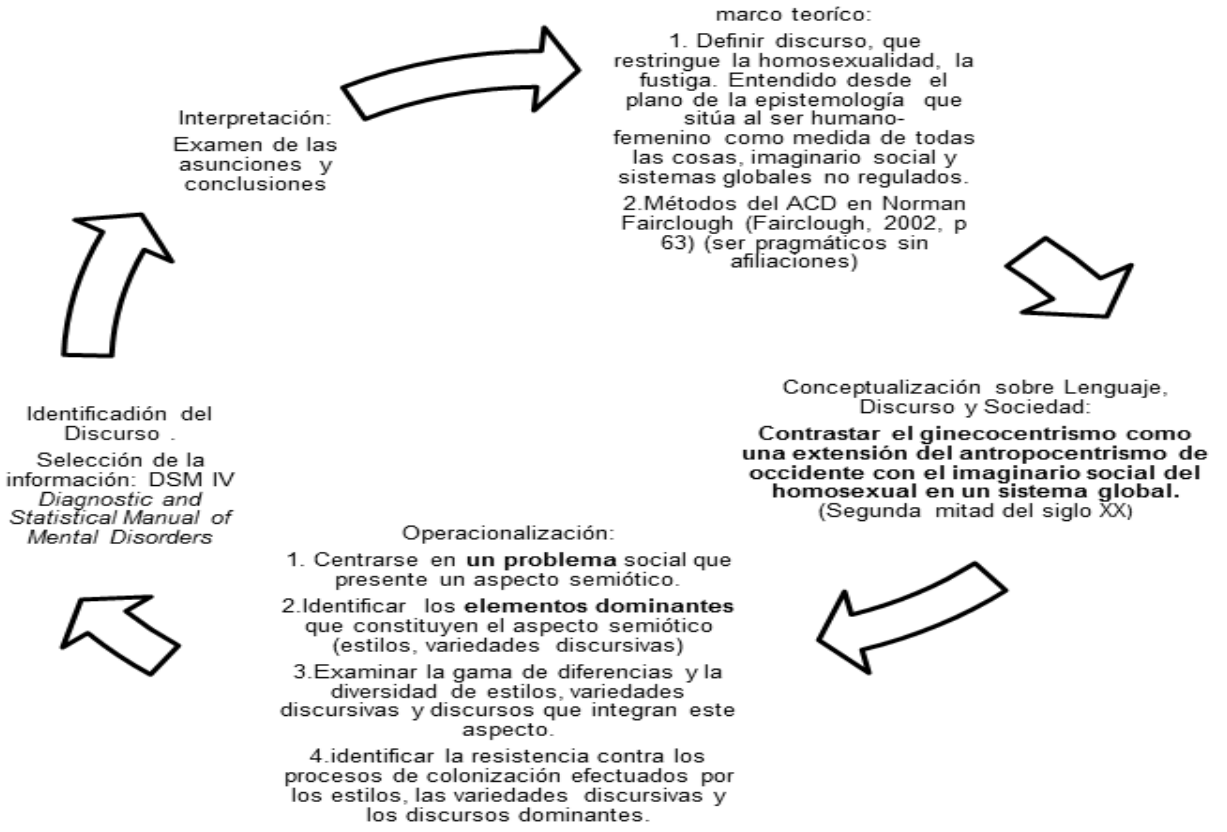

Fuente: Elaboración propia.

\section{Resultados}

En 1952, bajo la tutela de la praxis, el DSM I se configura por las necesidades contables y estadísticas de la morbilidad de los trastornos mentales posteriores a la segunda guerra mundial. No obstante, la utilidad clínica que tiene esta primera versión del manual le imprime "la seriedad de la cartilla que es la afasia del poder", como alguna vez lo afirmó Estanislao Zuleta (1980, p.30). Esa 
relación de lo visible (la cartilla) y lo que no se ve con tanta facilidad (el sistema de poder) puede establecerse mediante la siguiente cita respecto a la homosexualidad: "ha costado siglos poder afirmar abiertamente que no es una enfermedad, que no es una perturbación ni un delito, aunque costará algunos más confirmar que no es pecado para la mayoría de las confesiones religiosas" (Sánchez, 2011, p.246) que constituyen buena parte del imaginario colectivo.

En 1970 la convulsión social de Stone Wall dio lugar a la primera marcha de orgullo gay, en la que se reclamó la desvinculación de la homosexualidad del manual DSM. En este punto del texto y conforme a los cursos históricos, la desvinculación de la homosexualidad del manual es una resonancia política como se mostrara en párrafos posteriores. Ahora bien, las críticas que surgieron frente al DSM I no se referían a su configuración discursiva, sino a sus consecuencias plausibles: las terapias de reorientación o conversión sexual. Esto significa que el trabajo empírico que adelantaron los psiquiatras en los años setentas fue de vocación política, porque no buscaba controvertir los movimientos sociales en beneficio de las minorías teóricas: los homosexuales.

La psicóloga Evelyn Hooker publicó en 1957 su estudio La adaptación del hombre abiertamente homosexual, en el que se demostraba por primera vez que los hombres homosexuales no se distinguían de los heterosexuales por su salud mental. El psiquiatra Judd Marmor (1965), argumentó en su libro Inversión sexual: las múltiples raíces de la homosexualidad que "la actitud hacia la homosexualidad es determinada por la cultura" (p.70). La Asociación Psiquiátrica de Estados Unidos fundada en estos estudios decidió en 1973 desvincular la homosexualidad como rótulo del DSM para sus próximas revisiones. Sin embargo, no reconoció la actitud política que cobraba el momento sociocultural de los sesentas y setentas al tomar esta decisión.

Una de las figuras preponderantes dentro de esta decisión fue el psiquiatra Robert Spitzer (2001), quien señala que la clasificación de los trastornos mentales en categorías discretas con los criterios de diagnóstico especificados ha traído problemas. En el año 2001, Spitzer publicó un artículo científico titulado ¿Pueden algunos gays y lesbianas cambiar su Orientación Sexual? 200 participantes 
informaron un cambio de homosexual a heterosexual en el que estudió las terapias de reconversión sexual. En su trabajo se evidenció que la homosexualidad no tiene las características de una enfermedad mental, es decir, que no existe diagnóstico, ni un tratamiento; aunque doscientos participantes indicaron un cambio en su orientación sexual (Citado por Ritter, 2001, p.2).

3.1. Descripción del método de construcción del manual DSM IV y otras ejemplificaciones del problema de estudio ${ }^{7}$.

Siguiendo la sistematización propuesta en el apartado anterior, es preciso mencionar la metodología empírica que sigue dentro del manual para vislumbrar Ios aspectos discursivos más relevantes. El Comité elaborador del DSM-IV y los grupos de trabajo efectúan un proceso empírico a tres niveles que incluye: 1) revisiones sistemáticas de la literatura hasta ahora publicada, 2) re-análisis de los datos recogidos y 3 ) estudios de campo. A continuación, se presentarán diversos ejemplos discursivos en los que se apoya el desarrollo de la metodología propuesta en el presente texto y en el manual DSM.

El artículo de Spitzer (2001, p.3) y su postura discursiva en cuanto a la homosexualidad y las terapias que se reportaron en su estudio de 2001 corroboran la hipótesis represiva que supone el poder como un instrumento restrictivo, cuya mecánica es entorpecer o distorsionar la verdad. En este caso, el discurso individual pertenece a Robert Spitzer, pero, el discurso dominante es el del manual DSM. Es decir, aunque un individuo hable sobre el tema y devele su investigación, la forma institucionalizada cobra mayor peso respecto al diagnóstico y al consecuente tratamiento. Freud (1886) afirmó en una carta a una de sus clientas que deseaba tratar a su hijo homosexual y "que las terapias de reorientación sexual tienen consecuencias destructivas" (p.1). Además, dichas terapias tienen prohibiciones jurídicas en países como EEUU.

Con un estilo minucioso y actualizado, el método de revisión sistematizada del manual puede equipararse a las experiencias de Carl Vaernet y de Martin

\footnotetext{
${ }^{7}$ Parte uno (1) de la sistematización o desarrollo de la metodología: problema social que presenta aspectos semióticos, es decir, la producción de sentido, los significantes y los discursos dentro del manual DSM.
} 
Seligman (Seligman, 2002). El primer autor realizó experimentos médicos para tratar la homosexualidad con hormonas y dispositivos para su liberación en el campo de Buchenwald. El otro, se compara por su discurso de la mecánica económica de productividad y eficiencia encubierta por la "ciencia psicológica positiva de la felicidad" (Seligman, 2002, p.67). Una mezcla contra actual que está sujeta a una condición política dentro del discurso clínico.

En efecto, la metodología que se sigue para la construcción discursiva del manual es un círculo de retroalimentación en el que los significantes del discurso están presentes dentro de la sistematización, es decir, no abandonan el discurso. Se debe renunciar a la hipótesis de que el manual DSM IV no considera la homosexualidad como un trastorno, porque al evaluar su metodología el esquema de círculo hace que la representación discursiva sobre el homosexual este en revisión, o sea un trastorno ${ }^{8}$. Ahora bien, no se percibe como enfermedad, sino como un subproducto de la <conciliación> entre los valores y normas tradicionales, debido a que en la metodología para diagnosticar homosexualidad egodistónica se considera el grado de perturbación que reporta el paciente sobre su condición. Al respecto, cuando se nombra la palabra <condición>, de inmediato en el discurso se imprime la hipótesis central del presente texto.

Los pacientes que no hayan elaborado dicha concordancia serán considerados homosexuales egodistónicos o de orientación sexual egodistónica. Al hacer una lectura de las teorías de Judd Marmor no se debe considerar a la identificación y orientación sexual en un sistema de coherencia rígida, sino que se debe vislumbrar ese barniz de cultura que se tiene sobre el sexo, la sexualidad y la identidad. Asimismo, que son cosas que se relacionan pero que no son lo mismo; solo que la excesiva reducción o ampliación del discurso lleva consigo ciertas dislocaciones.

Todas las cargas simbólicas, discursivas y contextuales que se elaborar sobre la sexualidad, siguiendo la tesis de Foucault, se fabricaron desde un sistema represivo de doble espiral: poder y placer. Hablar de la represión hacía la homosexualidad, es un aire de transgresión que se mueve entre la <práctica> y la

\footnotetext{
${ }^{8}$ En la actualidad la representación discursiva que reposa sobre la homosexualidad es el estatus
} de revisión, diagnosticando a la homosexuales egodistónica, que finalmente es homosexualidad. 
<conciliación> con regímenes que suscitan la negación del mecanismo poderplacer. De acuerdo con Foucault (1977):

Hablar contra los poderes, decir la verdad y prometer el goce; ligar entre sí la iluminación, la liberación y multiplicadas voluptuosidades; erigir un discurso donde se unen el ardor del saber, la voluntad de cambiar la ley y el esperado jardín de las delicias; he ahí indudablemente lo que sostiene en nosotros ese encarnizamiento en hablar del sexo en términos de represión; he ahí lo que quizá también explica el valor mercantil atribuido no sólo a todo lo que del sexo se dice, sino al simple hecho de prestar el oído a aquellos que quieren eliminar sus efectos. (p.8).

3.2. Críticas al sistema DSM IV y los elementos dominantes dentro del discurso institucional.

El sistema global de referencia DSM IV no fustiga solamente a la homosexualidad de manera encubierta, lo mismo ocurre con las neo sexualidades: BDSM, poliamor, asexualidad, entre otras (Del Lagrace, 2005). En este documento se entiende por neo sexualidades aquellas que escapan a las "estructuras diádicas dominantes" (Burtle, 2002, p.78). Estas nuevas formas de ver la sexualidad son dinámicas y no se atan a la "coherencia" de la identificación sexual y la orientación sexual.

El apartado sobre los Trastornos sexuales y de la identidad sexual inicia con un preliminar que revela un discurso soslayado en el que "se describen las disfunciones sexuales, las parafilias y los trastornos de la identidad sexual" (Manual DSM IV, 1995, p.520). Se entiende por trastornos de identidad sexual a los transgéneristas, travestis, transexual y neo sexuales, dentro de los trastornos sexuales no especificados. En un principio la homosexualidad se consideró un desorden de la orientación sexual y su contrapartida, que es la identidad sexual, se comprende como un desequilibrio por extensión a la forma dominante del desorden psíquico.

Probablemente, la forma dominante (la homosexualidad) sigue manteniendo distancia social entre los médicos y los pacientes, y la autoridad del médico en cuanto a la forma en que se desarrolla la interacción. No obstante, existen otras formas que son más <<democráticas >>, formas en las que los médicos restan importancia a su autoridad (Wodak, 2002, p. 183). Le restan importancia al manual, pero sopesan el ejercicio de su profesión en él. La idea del 
sexo «reprimido» y las sexualidades «marginales» no son una simple cuestión de teoría y de manuales. El rigor del método multiaxial de valoración clínica se relaciona directamente con el énfasis discursivo sobre una represión de doble arista (placer y poder), que se destina a modificar las "conciliaciones» sobre el discurso clínico que representa el homosexual como objeto de estudio.

Bajo la premisa de las libertades sexuales «concedidas» bajo la tutela relativa de la psiquiatría y la política se pretenden señalar a las formas sutiles, pero muy astutas del poder. Un orden del discurso no es un sistema cerrado o rígido, sino más bien un sistema abierto que queda expuesto al peligro como consecuencia de lo que sucede en las interacciones efectivas (Wodak, 2002, p.183). La praxis y la disquisición del sistema de referencia conducen a una interacción semiótica entre una estructura discusiva y un enfoque clínico de control y polifonía del poder.

El modelo de los mecanismos tensionales y los refuerzos negativos de ideas pulsionales son los que se tipifican en el DSM. La prohibición de determinadas prácticas como el fetichismo, el voyerismo, la zoofilia, el exhibicionismo, la pansexualidad, el contemporáneo BDSM (sexualidad extrema no convencional) son dispositivos secundarios respecto al gran aparato de dominación: El diagnóstico y su respectivo tratamiento. Igualmente, la recriminación de la "homosexualidad egodistónica" y toda la censura impuesta por el sistema de referencia.

El estudio de las perversiones sexuales es una intensificación de los poderes porque se cree que aquellos que realizan actos abiertamente perversos carecen de la estabilidad emocional pertinente. Esto los hace diferentes 0 anormales, es decir, distintos de los normativizados que han elaborado sistemas de coherencia rígida y una conciliación moralmente compatible con las prácticas sociales. Además, la multiplicación de los discursos que analizan con minucia los excesos y las insatisfacciones sexuales siguen siendo ese organismo terapéutico que usa distinciones temporales arbitrarias, establece cánones de funcionalidad y productividad poco o nada ajustados a los contextos sociales. Contrario a ello, encuentra explicaciones totalitarias en los contextos sociales. 
El eretismo discursivo generalizado que describe Foucault se hace patente en el manual DSM y en la negación de algunos médicos psiquiatras de la hegemonía discursiva. Esta herramienta estandarizó las patologías de la mente y con argumentos cientificistas de tipo: «desordenes bioquímicos cerebrales» que aún no se pueden verificar y que han construido todo un aparato dominante. Un aforismo sencillo diría que la negación es aceptación por extensión.

La historia del manual DSM en la última década del siglo XX y la primera década del siglo XXI se asocia a la expansión comercial de los tratamientos vía fármacos. Es posible que se haya codificado todo el recetario que presenta el manual y se haya reafirmado de una manera acelerada la hipótesis represiva: la "aceptación" se determina como una prohibición encubierta para tornarla moralmente admisible y técnicamente lucrativa. Michel Foucault toma distancia de los hitos históricos como el neoliberalismo y la globalización para explicar los mecanismos y aparatos represivos. Las explicaciones macro distraen la atención al atribuirle todo el peso argumentativo a conceptos tan generales como los que se mencionaron antes.

Lo esencial del discurso no está en sus aspectos genéricos sino en la hipocresía que en ellos se sospeche. El lugar quejumbroso que le otorga el manual a las histerias femeninas se equipara al lugar que le da a la homosexualidad egodistónica, que no es cosa distinta a esa hipocresía y a esa actuación tolerable frente a la sexualidad y sus diversas manifestaciones que no pueden ser disímiles a la transgresión de las normas. Ahora bien, no vale hacer una división entre lo que el manual describe y las acciones investigativas de los psiquiatras porque esas fuentes de información se retroalimentan en un mutismo indisoluble. En efecto, lo que podría llamarse un discurso institucional se constituye todo el tiempo con las prácticas de comprobación (investigación sobre nuevas enfermedades mentales), de evaluación y de ridiculización (diagnóstico y tratamiento).

Las orto-dicciones del discurso psiquiátrico se evidencian en los mecanismo de confesión que se labran en la consulta médica. Además de los controles sociales que se ejercen con el lema de una vida sexual plena, en la que todas las 
publicaciones ciñen un canon que se aleja del homosexualismo y de las perturbaciones de unas prácticas normativas. Dichas ortopedias incitan el espiral poder - placer y también lo conservan en su seno institucional. En el caso del discurso psiquiátrico, la codificación implícita de los 'males' del sexo y las distorsiones de la sexualidad son las llamadas orto-dicciones al respeto de las normas contra el adulterio.

3.3. Técnicas polimorfas del poder en el manual DSM IV como las formas dominantes de discurso frente a las alternativas. Neo sexualidades sin discurso ${ }^{9}$.

Las prohibiciones, las censuras, los rechazos y las denegaciones que la hipótesis represiva reagrupa en un mecanismo central que dice no, sin duda son piezas de un papel global y táctico que desempeña el DSM en una técnica de poder. Esta no sólo subyace a la edición de enfermedades mentales, sino que permea todo un discurso sociopolítico que reafirma la hipótesis represiva que ha construido un imaginario de las sexualidades ubicándolas en las periferias del discurso, en lo que no es y es permitido.

Dentro de las técnicas que pueden dilucidarse las 'ilegalidades psiquiátricas' en la homosexualidad y en las neo sexualidades son los <conflictos> entre la identidad sexual - orientación sexual y el abanico de posibilidades que surgen por las combinaciones que se han tipificado como desviaciones asociadas. El manual reduce en el campo del lenguaje a lo que llama homosexualidad egodistónica, controla su libre circulación en el discurso como una apropiación médica del término psicológico egosintónico que referencia la coherencia con la autoimagen del individuo y apaga las palabras que hacen presente con demasiado vigor las alusiones a la homosexualidad y a las neo sexualidades, las enreda con especificaciones de receta.

Los efectos iatrogénicos de un discurso psiquiátrico sistemático continúan alimentándose. Puesto que la comorbilidad en la valoración multiaxial es posible, es decir, el discurso <práctico> del manual engendra imaginarios de

9 Parte tres y cuatro de la metodología descrita anteriormente. Se presentan las maneras discursivas del manual frente a las neo sexualidades que carecen de un discurso, es decir, la forma dominante e institucional frente a las prácticas no convencionales. 
enfermedades mentales que coexisten con la homosexualidad egodistónica o con el travestismo. Cabe resaltar, que en las especificaciones técnicas y metodológicas del DSM IV se hacen ciertas salvedades 'culturales' que prometen librarse de los sesgos del discurso, sin embargo, la histerización de los cuerpos dentro del manual es tal que la valoración de un síntoma frecuente la dictan seis meses de inconformidad con los valores y normas tradicionales, que se leen en el discurso del DSM IV como una incoherencia con la imagen del individuo y no con el sistema moral predominante.

Las formas del poder en el DSM se podrían clasificar en cuatro formas distintas a la censura soslayada. La primera de ellas es la propagación del poder y del objeto sobre el que se ejerce, es decir, enseñar a los psiquiatras el uso del manual y apoyarlo sobre los enfermos (estudios de campo). La segunda es el hostigamiento de las neo sexualidades (investigaciones sobre la sexualidad extrema no convencional), además de la caracterización de las perversiones. La tercera es el mecanismo de la concesión o <aceptación> de la homosexualidad (revisión del tema por parte del comité elaborador del manual), pero no del travestismo. Finalmente, las instituciones de control como los grupos de investigación que alimentan al manual y los supuestos vacíos del manual que nutren a los grupos o científicos de las ciencias de la mente (El círculo de retroalimentación que se nombró anteriormente).

Foucault se pregunta: “¿cómo se logró constituir esa inmensa y tradicional extorsión de confesión sexual en formas científicas?" (Foucault, 1999, p. 98). E examen multiaxial del que tanto se ha hablado en el documento se entiende como esos nuevos métodos del hacer hablar y que da lugar a la existencia de los demás mecanismos de control. Un accidente, una desviación, un trauma o un exceso pueden conducir a un sujeto a una enfermedad mental. No obstante, la latencia de la sexualidad también es un argumento en beneficio de la caracterización de la enfermedad, es decir, la forclusión de un significante fundamental en relación al sexo. 
En este punto se hace evidente el sistema de los mecanismos de refuerzos tensionales que se diagnostican y medican, en una relación negativa entre poder y sexo, limite y carencia. La regla que subyace al sistema de estandarización de los males de la mente y de la sexualidad es el poder. Para Foucault el poder es esencialmente lo que dicta al sexo su ley.

Por otra parte, Sloterdijk (1983) en su texto Crítica de la razón cínica presenta como las "prescripciones de prudencia" (Citado por Foucault, 1998, p.79) que señala Foucault en La Historia de la Sexualidad I no se hacen patentes en este caso de estudio. Los bloques tácticos del discurso y de los focos poder-saber, placer-poder revelan un doble condicionamiento (Foucault, 1998), pero de una manera cínica, como un recetario de antipsicóticos, ansiolíticos y antidepresivos en un mercado de cajas negras y agujeros argumentativos de la ciencia psiquiátrica.

\section{Conclusiones}

El análisis de contenidos $^{10}$ que se describió en la metodología y su consecuente desarrollo en el apartado de resultados y las críticas que se elaboraron en torno al DSM IV permiten vislumbrar el debilitamiento de las restricciones morales sobre la homosexualidad, como se aseguró en la introducción. No obstante, las "significaciones" (cfr. Burtle, 2002, p.140) del travestismo y de las neo sexualidades dan cuenta del nivel de falsa indulgencia que se le otorga a la orientación y a la identificación sexual. En este paraje puede afirmarse que la cantidad de represión sobre el sexo y sus formas son fruto de la histerización (cfr. Burtle, 2002, p.100) de los cuerpos como referencias válidas para editar perversiones y plasmarlas en un manual.

Tal es el caso de Richard von Krafft-Ebing (Krafft-Ebing, 1905, p.5), un psiquiatra que dedico todo su trabajo a especificar, a calificar, a apreciar y a jerarquizar las perversiones sexuales. En su texto Psicopatía del sexo de 1886, se

\footnotetext{
${ }^{10} \mathrm{El}$ análisis de discurso acotado que se efectuó resalto el discurso dominante (manual DSM IV) frente a las formas no discursivas sino prácticas (neo sexualidades). Sus categorías resaltan los aspectos estilísticos del discurso que para el caso de estudio son neutros, las tendencias que son de discurso de diagnóstico directo a diagnostico soslayado como se nombró en el texto.
} 
identifica la paradoxia, o el deseo sexual experimentado en etapas de la vida equivocadas, la anesthesia como escasez de deseo, la hyperesthesia que es deseo excesivo y la paraesthesia que es el deseo sexual sobre un objeto equivocado donde se incluía la homosexualidad. Este es, quizá, uno de los referentes más parecidos a lo que se conoce en la actualidad como el Manual diagnóstico y estadístico de los trastornos mentales. Es preciso afirmar que fruto de las nuevas investigaciones se sigue medicando bajo los preceptos de 1886 quitando la palabra homosexualidad del manual por ser un tema de carácter político acentuado. En conclusión, el esquema circular descrito sigue operando, manteniendo la representación y la significación discursiva.

La reconsideración que se plantea es ¿qué sucedería con la institución del manual si se quitara el travestismo y las neo sexualidades como trastornos de la mente? La homosexualidad se editó llegando a la forma egodistónica, recordando la hipótesis represiva Foucaultiana. Al realizar un análisis del contenido del documento clínico de referencia se observa como el <equilibrio> discursivo se alteró, quizá, si el travestismo se elimina del manual será muy evidente la desconstrucción discursiva y el esquema del círculo sería seccionado. Finalmente, la bisección sería completa porque se desmantelaría de una red que tiene como centro que el objetivo del deseo sexual es la procreación y que cualquier forma de deseo que no tiene como fin último la fecundidad o las insinuaciones simbólicas de la misma, es una perversión. Por ello, la violación es un acto aberrante, pero no una perversión, porque de ella podría derivarse el embarazo. Otro ejemplo sobresaliente, son las expresiones estéticas travestidas que rayan con lo socialmente inaceptable y lo extraño que debe medicarse porque resulta aberrante y perverso.

Otro argumento que apoya la reconsideración de los imaginarios sobre el homosexual en el manual de trastornos es la tesis que Philippe Ariés (1987) retoma de Michael Pollak sobre los modelos de la sociedad. Estos autorespresentan las representaciones que de sí mismos hacen los homosexuales y plantean que esta concordancia se debe a la deformación de las imágenes y los papeles. Dicha distorsión podría explicarse desde el fracaso de los modelos de la 
matriz heterosexual (modelos patriarcales, matriarcales) debidos al cambio de la antropología de la virilidad y la feminidad. También se registran las mutaciones del trabajador y del tipo que explica Ernst Jünger en su texto El trabajador, Dominio y Figura, que sin duda alguna ha modificado el imaginario hacia la "aceptación" y es allí donde los temas de la ciencia psiquiátrica se ven languidecer. La tolerancia frente a la homosexualidad derivaría de un cambio en la representación de los sexos, no sólo de sus funciones, de sus roles en la profesión y en la familia sino de sus imágenes simbólicas (Ariés, 1987).

La hiper-saturación de los discursos sobre la sexualidad tolerada deriva de las variaciones en las representaciones sociales del homosexual; no obstante, el discurso clínico es fiel a su puritanismo, en contrapartida de su hipocresía. Un discurso construido de esa manera no puede ser más que la expresión de los dispositivos poder-placer-saber que se han implantado desde la ciencia psiquiátrica. El solo hecho de que se haya pretendido hablar desde el punto de vista neutro de una ciencia es en sí incapacidad o rechazo al hablar del sexo mismo, Foucault (1998) se refirió sobre todo a aberraciones, perversiones, rarezas excepcionales, anulaciones patológicas, exasperaciones mórbidas.

Pese a los cambios conceptuales y jurídicos sobre la homosexualidad, las neosexualidades no se inscriben en ese mundo de transformaciones. Ello debido a que las relaciones intersubjetivas que no están normativizadas en una esfera heterosexista siguen siendo discriminadas: son un tabú.

Ahora bien, el sistema DSM IV en relación a la homosexualidad y de manera distinta con las neosexualidades asume una <conciliación>, entre el sistema social y moral dominante y el afectado. La cuestión es que el travestismo, por ejemplo, es de una estética fuerte que no concilia con facilidad con ese sistema social y moral. Lo que reduciría el problema, en principio, a una correlación débil entre estética y ética en el caso citado. No obstante, el manual psiquiátrico DSM IV no lo asume de esa manera, por ser una receta de morbilidad con fines estadísticos. 


\section{Referencias Bibliográficas}

Althusser, L. (2003). Ideología y aparatos ideológicos de estado. Buenos Aires: Nueva Visión.

Alcott, A. (1836). The young man's guide. Boston: Perkins and Marvin.

Ariés, P. (1987). Sexualidades occidentales. Barcelona: Paidós.

Barragán, R. (2005). Presencia de los lenguajes no verbales en el área de lengua castellana. En F. Vásquez (ed.). La didáctica de la lengua: estado de la discusión en Colombia. Cali, Colombia: Universidad del Valle.

Babiszenko, D. y Lutereau, L. (2011). La homosexualidad femenina en el psicoanálisis de J. McDougall. Psicoanálisis. Argentina: Universidad de Buenos Aires.

Bataile, G. (1978). Historia del ojo. España: Tusquets.

Barthes, R. (1974). La semiología. Buenos Aires: Tiempo Contemporáneo.

Barthes, R. (1973). Por ambas partes, Ensayos críticos. Barcelona: Seix Barral.

Beck, U. (1994). Modernización Reflexiva. Madrid: Alianza Editorial

Burtle, J. (2002). Cuerpos que importan: sobre los límites materiales y discursivos del "sexo". Buenos Aires: Paidós.

Burtle, J. (2009). Dar cuenta de sí mismo. Violencia ética y responsabilidad. Buenos Aires: Amorrortu.

Colorado, C. (2010). Una mirada al Análisis Crítico del Discurso. Entrevista con Ruth Wodak. Discurso \& Sociedad, 4 (3), 579-596.

Del Lagrace, V. (2005). Corpus queer: bodies in resistance, Transpalette, Emmetrop. Bourges: France September 2005. (exhibitions).

Del Lagrace, V. (2005). Intersex 101: The Two Gender System as a Human Rights Abuse, NGBK gallery, Berlin: Germany June 2005. (exhibitions).

Asociación Americana de Psiquiatría (Estados Unidos). (1994). DSM IV, Manual diagnóstico y estadístico de los trastornos mentales.

Fairclough, N. (2001). Language and Power. Londres: Longman.

Fairclough, N. (2003). Analysing Discourse: Textual Analysis for Social Research. Londres: Routledge.

Foucault, M. (1988). Las palabras y las cosas. México: Siglo XXI. 
Foucault, M. (1998). Historia de la sexualidad I: La voluntad de saber. México: Siglo XXI.

Halberstam, J. (2005). In a Queer Time and Place: Transgender Bodies, Subcultural Lives. New York: New York University Press.

Halberstam, J. (2003). "The Transgender Look." in The Bent Lens: A World Guide to Gay and Lesbian Film. Los Angeles, CA: Alyson Books.

Hooker, E. (1957). The adjustment of the male overt homosexual, "Journal of projective techniques". (paper).

Innis, H. (1952). Changing Concepts of Time. Toronto: University of Toronto Press. Jiménez, R. (2012). La génesis de las parafilias sexuales y la homosexualidad egodistónica: el Modelo de los Mecanismos Tensionales. Avances en Psicología Latinoamericana. España: Universidad de Málaga.

Jünger, E. (1990). El Trabajador. Madrid: Tusquest.

Krafft-Ebing, R. (1999). Psychopathia Sexualis. Alemania: Bloat Books.

Kaiser, C. (1997). The Gay Metropolis. Broadway: Group West.

Gamboa, I. (2006). La Constitución de Trastornos Sexuales en la Psiquiatría. Diálogos, 7 (1), 242 - 290.

Gee, J. (2005). La ideología en los discursos. Madrid: Morata.

González, C. (2001). La identidad gay: una identidad en tensión", Saberes y Razones primavera-verano.

Martín, M. (2008). Aproximación histórica al tratamiento jurídico y social dado a la homosexualidad en Europa. Estudios Constitucionales. Centro de Estudios Constitucionales de Chile Universidad de Talca "Aproximación histórica al tratamiento jurídico y social dado a la homosexualidad en Europa".

Marmor, J. (1972). Homosexuality in males. International Journal of Psychiatry, 10 (1).

Marmor, J. (1972). Homosexuality mental illness or moral dilemma? International Journal of Psychiatry, 10 (1).

Preciado, B. (2009). Historia de una palabra. Ensayo. Madrid: Anagrama.

Preciado, B. (2009). Género y basura. Ensayo. Madrid: Anagrama. 
Ritter, M. (2001, 11 de octubre). Study: Some Gays Can Go Straight. The Washington Post. Recuperado de http://www.washingtonpost.com/wpsrv/aponline/20010509/aponline013921 000.ht $\underline{\mathrm{m}}$

Rodríguez, A. (2013). Las escaleras de escher: la transversalización de género vista desde las capacidades del estado. Estudios de Género CEPAL.

Rojas, M. (2006). El imaginario. Civilización y cultura del siglo XXI. Buenos Aires: Prometeo.

Sáez, J. (2013). Guía para la gestión policial de la diversidad. Madrid: Editorial Plataforma por la Gestión policial de la Diversidad.

Sáez, J. (2013). Discriminación y Comunidad Gitana. Madrid: Editorial Plataforma por la Gestión policial de la Diversidad.

Seligman, M. (2002). Authentic Happiness: Using the New Positive Psychology to Realize Your Potential for Lasting Fulfillment. New York: Free Press.

Sloterdijk, P. (1983). Crítica de la razón cínica. Madrid: Siruela.

Spitzer, R. (2001). Can Some Gay Men and Lesbians Change Their Sexual Orientation? 200 Participants Reporting a Change from Homosexual to Heterosexual Orientation. Biometrics Research Department, NewYork State Psychiatric Institute, New York, New York. Department of Psychiatry, Columbia University. (paper).

Téllez, F. (2012). Narración audiovisual transnacional en la homosexualidad. Comunicación: revista Internacional de Comunicación Audiovisual, Publicidad y Estudios Culturales. España: Universidad de Sevilla.

Téllez, F. (2013). Culturas homoeróticas televisadas. Ponencia presentada en III Congreso "ciencias, tecnologías y culturas. Dialogo entre las disciplinas del conocimiento. Mirando al futuro de América Latina y el Caribe. Hacia una internacional del conocimiento. Chile: Universidad Santiago de Chile. Van Dijk, T. (2000). Estudios del discurso. Buenos Aires: Gedisa. Van Dijk, T. (2011). Sociedad y Discurso: Cómo influyen los contextos sociales sobre el texto y la conversación. Barcelona: Gedisa. 
Van Dijk, T. (2012). Discurso y Contexto. Una aproximación cognitiva. Barcelona: Gedisa.

Vidarte, F. (2007). Ética Marica. Proclamas libertarias para una militancia LGTBQ. Madrid: Egales.

Vidarte, F. (1999). Homografías. Madrid: Espasa-Calpe.

Wittig, M. (1973). El cuerpo lesbiano. España: Pre-Textos.

Wodak, R. (2002). Methods of Critical Discourse Analysis (Introducing Qualitative Methods series). EEUU: Sage Publications.

Zuleta, E. (2000). Elogio a la dificultad y otros ensayos. Cali: Fundación Estanislao Zuleta. 